\title{
PELAKSANAAN TUGAS KADER TUBERKULOSIS DI KABUPATEN BADUNG TAHUN 2019
}

\author{
Ni Wayan Emi Liana Anggraeni*, Made Pasek Kardiwinata \\ Program Studi Sarjana Kesehatan Masyarakat Fakultas Kedokteran Universitas Udayana \\ *)email : anggreniiemii@gmail.com
}

\begin{abstract}
ABSTRAK
Upaya pengendalian secara pasif oleh petugas kesehatan masih belum dapat menekan angka tuberkulosis di Kabupaten Badung. Dibutuhkan adanya kegiatan penemuan kasus secara aktif serta pendampingan pasien selama menjalani pengobatan lengkap yang lebih optimal, tidak hanya dari petugas pemegang program namun juga dibutuhkan peran serta dari masyarakat, salah satunya adalah dengan memanfaatkan tenaga kader. Keberhasilan pelaksanaan tugas kader memiliki peran penting dalam membangun kerja sama dengan petugas kesehatan untuk menekan kejadian tuberkulosis. Tujuan penelitian ini untuk mengetahui pelaksanaan tugas kader TB di Kabupaten Badung tahun 2019. Desain penelitian ini adalah observasional cross-sectional deskriptif. Sampel dalam penelitian ini adalah seluruh kader TB yang ada di Kabupaten Badung berjumlah 50 orang. Data diperoleh dengan teknik wawancara menggunakan kuesioner. Hasil penelitian menunjukkan bahwa pelaksanaan tugas kader TB masih kurang yang disebabkan oleh kurangnya keterlibatan kader TB dalam pendampingan pengobatan. Diantara pelaksanaan tugas yang kurang tersebut, dijumpai temuan bahwa kader TB yang berjenis kelamin laki-laki, memiliki pekerjaan selain sebagai kader TB serta memiliki tingkat pengetahuan baik, cenderung memiliki pelaksanaan tugas yang baik. Disarankan bagi instansi terkait dalam perekrutan kader selanjutnya agar lebih memprioritaskan kader berjenis kelamin laki-laki dikarenakan kebanyakan tugas dari kader TB berada di luar ruangan.
\end{abstract}

Kata Kunci : Pelaksanaan tugas, Kader, TB

\section{ABSTRACT}

Passive control efforts by health workers still cannot reduce the rate of tuberculosis in Badung Regency. Active case-finding activities are needed as well as mentoring patients while undergoing more optimal complete treatment, not only from program officers but also from the community's participation, one of which is to use community TB workers. The successful implementation of work perfomance community TB workers has a very important role in building cooperation with health workers to reduce the incidence of tuberculosis. This study aims to determine the Implementation of Work Perfomance Community TB Workers in Badung Regency 2019. The design of this study was cross-sectional observational descriptive. The sample in this study was that all tuberculosis cadres in Badung Regency gathered 50 people. Data obtained by interview techniques using questionnaires. The results showed that the implementation of TB cadre assignments was still lacking caused by the involvement of TB cadres in treatment assistance. Among the implementation of these lacking tasks, found the finding that TB cadres who are male, have jobs other than as TB cadres and have a good level of knowledge, need to have good implementation tasks. Furthermore, further submissions for male cadres greater than the TB cadre assignments were outdoors.

Key Word : Job, cadre, TB

\section{PENDAHULUAN}

Selama penerapan strategi DOTS yang direkomendasikan oleh WHO sejak tahun 1995 dalam menanggulangi penyakit tuberkulosis yang terfokus pada penemuan serta upaya penyembuhan terhadap pasien terbukti masih belum dapat berjalan dengan baik (Anisah dkk, 2017). Dalam penanggulangan TB sebelumnya, penemuan penderita tuberkulosis dilakukan secara pasif atau kegiatan penemuan tersangka tuberkulosis hanya dilakukan pada penderita yang datang ke Puskesmas saja sedangkan penderita yang belum maupun tidak datang ke Puskesmas masih menjadi sumber penularan yang tersebar di masyarakat luas (Nisa dkk, 2017). 
Target CNR Tuberkulosis di Kabupaten Badung pada tahun 2018 sebesar $87 \%$ sedangkan capaian yang diperoleh adalah sebesar $74,74 \%$ yang berarti belum dapat mencapai target (Dinas Kesehatan Kabupaten Badung, 2018). Dibutuhkan adanya peningkatan cara penemuan kasus serta pengobatan yang lebih memadai agar dapat memenuhi target penanggulangan tuberkulosis yang belum tercapai (Abshor, 2018). Keberhasilan dari pelaksanaan penanggulangan Tuberkulosis di masyarakat membutuhkan adanya keterlibatan dari berbagai pihak, tidak hanya dari petugas kesehatan namun juga berasal dari masyarakat. Dukungan dan peran serta masyarakat sangat membantu dalam menanggulangi tuberkulosis sebagai salah satu langkah penemuan serta pendampingan pengobatan pada pasien TB secara aktif (Yani dkk, 2018). Salah satu langkah yang dapat ditempuh guna memberdayakan masyarakat agar terlibat aktif pada penanggulangan penyakit tuberkulosis adalah dengan membentuk kader TB (Megawati, 2018).

Penemuan kasus secara aktif yang dilakukan oleh kader TB memiliki keunggulan dibandingkan dengan penemuan kasus secara pasif yaitu dapat dengan cepat serta tepat dalam menemukan penderita tuberkulosis pada kelompok masyarakat yang merasa enggan untuk memeriksakan diri (Nisa dkk, 2017). Adanya kader TB yang mendampingi masyarakat bertujuan agar dapat menekan angka pasien yang putus berobat, meningkatkan penemuan kasus tuberkulosis dan meningkatkan kesembuhan penderita serta menghapuskan stigma negatif masyarakat terhadap penderita tuberkulosis yang memungkinkan terhambatnya program pengendalian tuberkulosis yang sedang digalakkan (Yani dkk, 2018).

Angka kesembuhan pasien TB yang memanfaatkan tenaga kader TB menunjukkan peningkatan apabila dibandingkan dengan angka kesembuhan pasien TB yang tidak memanfaatkan tenaga kader TB (Ong'ang'o, 2014). Oleh karena itu, keberhasilan pelaksanaan tugas kader TB menjadi penting untuk dicapai agar dapat terjalinnya kerjasama yang baik dengan petugas kesehatan dalam menanggulangi penyakit tuberkulosis. Pembentukan kader TB di Kabupaten Badung ini merupakan salah satu langkah pencegahan baru yang diusung oleh PPTI (Perkumpulan Pemberantasan Tuberkulosis Indonesia) cabang Badung bekerjasama dengan Dinas Kesehatan Kabupaten Badung dalam menekan kasus tuberkulosis melalui pemberdayaan masyarakat itu sendiri. Selain itu, dengan pembentukan kader TB ini diharapkan dapat lebih meningkatkan pengetahuan serta kepedulian masyarakat terhadap pemberantasan penyakit TB di Kabupaten Badung.

Tujuan dilakukannya penelitian ini adalah untuk mengetahui distribusi frekuensi pelaksanaan tugas, mengetahui distribusi frekuensi tingkat pengetahuan, distribusi frekuensi karakteristik sosiodemografi seperti umur, jenis kelamin, pendidikan, pekerjaan, reward yang diperoleh dan riwayat pelatihan serta untuk mengetahui distribusi frekuensi 
karakteristik sosio-demografi dan tingkat pengetahuan terhadap pelaksanaan tugas kader TB di Kabupaten Badung tahun 2019.

\section{METODE PENELITIAN}

Penelitian ini menggunakan desain crosssectional deskriptif dengan menggambarkan pelaksanaan tugas kader TB di Kabupaten Badung. Penelitian ini dilaksanakan dalam waktu 5 bulan, mulai dari bulan Januari hingga bulan Mei 2019 dengan lokasi penelitian dilaksanakan di seluruh puskesmas se-Kabupaten Badung. Sampel dalam penelitian ini adalah kader TB di Kabupaten Badung yang dipilih menggunakan total population sampling dengan jumlah sampel yang diperoleh sebesar 50 orang kader TB. Kriteria inklusi dalam penelitian ini adalah kader TB yang masih aktif bekerja dari masing-masing Puskesmas yang bekerjasama dengan PPTI di Kabupaten Badung dan bersedia menjadi responden dalam penelitian ini. Kriteria eksklusi dalam penelitian ini adalah kader TB yang tidak bersedia untuk menjadi responden.

Dalam penelitian ini menggunakan data primer, diperoleh secara langsung Tabel 1. Distribusi Frekuensi Pelaksanaan Tugas Kader TB di Kabupaten Badung

\begin{tabular}{lcc}
\hline Pelaksanaan Tugas & Frekuensi & Persentase $(\%)$ \\
\hline Kurang & 31 & 62 \\
Baik & 19 & 38 \\
\hline Total & 50 & 100 \\
\hline
\end{tabular}

Kader TB di Kabupaten Badung sebagian besar masih belum dapat melaksanakan tugas sebagai kader dengan baik yaitu sebanyak 31 responden (62\%), oleh peneliti melalui proses wawancara dengan menggunakan instrumen penelitian untuk seluruh sampel penelitian yang telah ditentukan. Instrumen penelitian yang digunakan dalam penelitian ini adalah kuesioner yang memuat tentang karakteristik, tingkat pengetahuan serta pelaksanaan tugas kader TB. Data dalam penelitian ini dianalisis secara univariat dan tabulasi silang hingga menghasilkan informasi berupa frekuensi serta persentase dari masing-masing variabel dalam penelitian yang kemudian akan dijabarkan dalam bentuk distribusi frekuensi.

\section{HASIL}

Responden dalam penelitian ini adalah seluruh kader TB yang direkrut oleh PPTI cabang Badung bekerja sama dengan Dinas Kesehatan Kabupaten Badung serta ditugaskan pada seluruh Puskesmas di Kabupaten Badung. Gambaran pelaksanaan tugas, pengetahuan serta karakteristik sosiodemografi dari kader TB adalah sebagai berikut : 
Tabel 2. Distribusi Frekuensi Karakteristik Sosio-Demografi Kader TB di Kabupaten Badung

\begin{tabular}{ccc}
\hline Karakteristik Kader TB & Frekuensi & Presentase (\%) \\
\hline Umur & 32 & 64 \\
$\leq 40$ tahun & 18 & 36 \\
$>40$ tahun & & \\
Jenis Kelamin & 41 & 82 \\
Perempuan & 9 & 18 \\
Laki-laki & & \\
Pendidikan & 32 & 64 \\
Rendah & 18 & 36 \\
Tinggi & & \\
Pekerjaan & 10 & 20 \\
Tidak Bekerja & 40 & 80 \\
Bekerja & & \\
Reward & 16 & 32 \\
Belum pernah & 34 & 68 \\
Pernah & & \\
Pelatihan & 26 & 52 \\
Kurang & 24 & 48 \\
Baik & & \\
Pengetahuan & 14 & 28 \\
Kurang & 36 & 72 \\
Baik & & \\
\hline
\end{tabular}

Berdasarkan distribusi frekuensi karakteristik kader TB dapat diketahui bahwa sebagian besar kader TB di Kabupaten Badung berada pada usia $\leq 40$ tahun sebanyak 32 responden (64\%) serta berjenis kelamin perempuan sebanyak 41 responden (82\%). Tingkat pendidikan kader TB di Kabupaten Badung mayoritas berada pada kategori pendidikan rendah sebanyak 32 responden (64\%), selain itu sebagian besar kader TB memiliki pekerjaan lain selain bekerja sebagai kader yaitu sebanyak 40 responden (80\%).
Sebagian besar kader TB juga sudah pernah memperoleh reward selama bekerja sebagai kader yaitu sebanyak 34 responden $(68 \%)$ serta sebagian besar kader memiliki riwayat pelatihan kurang yaitu sebanyak 26 responden (52\%). Kader TB di Kabupaten Badung dominan memiliki pengetahuan baik tentang pelaksanaan tugas kader TB yaitu sebanyak 36 responden $(72 \%)$, sedangkan masih terdapat 14 responden (28\%) yang memiliki pengetahuan kurang tentang pelaksanaan tugas kader TB.

Tabel 3. Distribusi Frekuensi Karakteristik Sosio-Demografi dan Pengetahuan Terhadap Pelaksanaan Tugas Kader TB di Kabupaten Badung

\begin{tabular}{|c|c|c|c|c|c|c|}
\hline \multirow{3}{*}{ Variabel } & \multicolumn{4}{|c|}{ Pelaksanaan Tugas Kader TB } & \multirow{2}{*}{\multicolumn{2}{|c|}{ Total }} \\
\hline & \multicolumn{2}{|c|}{ Kurang } & \multicolumn{2}{|c|}{ Baik } & & \\
\hline & $\mathrm{f}$ & $\%$ & $\mathrm{f}$ & $\%$ & $\mathrm{f}$ & $\%$ \\
\hline Umur & & & & & & \\
\hline$\leq 40$ tahun & 22 & 68,75 & 10 & 31,25 & 32 & 100,00 \\
\hline$>40$ tahun & 9 & 50,00 & 9 & 50,00 & 18 & 100,00 \\
\hline
\end{tabular}




\begin{tabular}{lcccccc}
\hline Jenis Kelamin & & & & & & \\
$\quad$ Perempuan & 29 & 70,73 & 12 & 29,27 & 41 & 100,00 \\
$\quad$ Laki-laki & 2 & 22,22 & 7 & 77,78 & 9 & 100,00 \\
$\begin{array}{l}\text { Pendidikan } \\
\quad \text { Rendah }\end{array}$ & 19 & 59,38 & 13 & 40,63 & 32 & 100,00 \\
$\quad \begin{array}{l}\text { Tinggi } \\
\text { Pekerjaan }\end{array}$ & 12 & 66,67 & 6 & 33,33 & 18 & 100,00 \\
$\quad$ Tidak bekerja & 10 & 100,00 & 0 & 00,00 & 10 & 100,00 \\
$\quad$ Bekerja & 21 & 52,50 & 19 & 47,50 & 40 & 100,00 \\
$\begin{array}{l}\text { Reward } \\
\quad \text { Belum pernah }\end{array}$ & 9 & 56,25 & 7 & 43,75 & 16 & 100,00 \\
$\quad$ Pernah & 22 & 64,71 & 12 & 35,29 & 34 & 100,00 \\
$\begin{array}{l}\text { Riwayat Pelatihan } \\
\quad \text { Kurang }\end{array}$ & 17 & 65,38 & 9 & 34,62 & 26 & 100,00 \\
$\quad$ Baik & 14 & 58,33 & 10 & 41,67 & 24 & 100,00 \\
$\begin{array}{l}\text { Pengetahuan } \\
\quad \text { Kurang }\end{array}$ & 13 & 92,86 & 1 & 7,14 & 14 & 100,00 \\
$\quad$ Baik & 18 & 50,00 & 18 & 50,00 & 36 & 100,00 \\
\hline
\end{tabular}

Berdasarkan distribusi frekuensi karakteristik sosio-demografi terhadap pelaksanaan tugas kader TB, dapat diketahui bahwa kader TB pada kelompok usia $\leq 40$ tahun yang belum dapat melaksanakan tugas dengan baik sebanyak $68,75 \%$. Kader TB pada kelompok usia $>40$ tahun yang belum dapat melaksanakan tugas dengan baik sebanyak 50,00\%. Dilihat dari jenis kelamin, dapat diketahui bahwa kader TB yang berjenis kelamin perempuan dan belum dapat melaksanakan tugas dengan baik sebesar $70,73 \%$, sedangkan kader TB yang berjenis kelamin laki-laki dan belum dapat melaksanakan tugas dengan baik sebesar $22,22 \%$.

Berdasarkan tingkat pendidikan, dapat diketahui bahwa kader TB yang tingkat pendidikannya tergolong rendah dan pelaksanaan tugasnya masih kurang sebanyak 59,38\%. Kader TB yang tingkat pendidikannya tergolong tinggi dan pelaksanaan tugasnya kurang sebanyak $66,67 \%$. Dilihat dari status pekerjaan, dapat diketahui bahwa kader TB yang tidak memiliki pekerjaan lain serta belum dapat melaksanakan tugas dengan baik sebesar 100,00\%, sedangkan kader TB yang memiliki pekerjaan lain serta belum dapat melaksanakan tugas dengan baik sebesar $52,50 \%$.

Dilihat dari reward yang diperoleh, dapat diketahui bahwa kader TB yang belum pernah memperoleh reward dan belum dapat melaksanakan tugas dengan baik sebesar $56,25 \%$, sedangkan kader TB yang sudah pernah memperoleh reward dan belum dapat melaksanakan tugas dengan baik sebesar $64,71 \%$. Berdasarkan riwayat pelatihan, dapat diketahui bahwa kader TB dengan riwayat pelatihan kurang yang belum dapat melaksanakan tugas dengan baik sebesar 65,38\%, sedangkan kader TB dengan riwayat pelatihan baik yang belum dapat melaksanakan tugas dengan baik sebesar 58,33\%. Kader TB yang memiliki pengetahuan kurang dan belum dapat melaksanakan tugas dengan baik sebesar $92,86 \%$. Kader TB yang 
memiliki pengetahuan baik dan belum dapat melaksanakan tugas dengan baik sebesar $50,00 \%$.

\section{DISKUSI}

Pelaksanaan tugas kader TB di Kabupaten Badung sebagian besar masih kurang. Tingginya persentase kader TB yang belum dapat melaksanakan tugas dengan baik sebagian besar disebabkan oleh kurangnya keikutsertaan kader TB dalam kegiatan evaluasi pendampingan pengobatan pada pasien TB. Hal ini dikarenakan sebagian besar kader TB masih belum terlibat aktif dalam kegiatan pendampingan pengobatan pada pasien TB. Mayoritas kader TB di Kabupaten Badung yang melakukan pendampingan pengobatan adalah kader TB yang merangkap sebagai petugas lapangan PPTI, ditugaskan pada seluruh Puskesmas di Kabupaten Badung serta telah terlatih baik dari segi teori maupun praktek di lapangan terkait dengan pendampingan pengobatan pada pasien TB. Hal ini sejalan dengan pernyataan Nisa dkk (2017) bahwa PMO yang dipilih dalam mendampingi pasien TB sebagian besar merupakan PMO yang telah terlatih dan atau merupakan anggota keluarga pasien sehingga mempunyai kesadaran yang lebih tinggi dalam mendampingi pengobatan pasien TB.

Dilihat dari karakteristik umur, kader TB pada kelompok umur $\leq 40$ tahun maupun pada kelompok umur $>40$ tahun sama-sama menunjukkan bahwa sebagian besar pelaksanaan tugasnya masih kurang. Pelaksanaan tugas kader TB tidak didasari oleh batasan umur. Nisa dkk (2017) menyatakan dalam penelitiannya bahwa usia kader kesehatan tidak memiliki pengaruh terhadap praktik penemuan tersangka kasus tuberkulosis paru. Walaupun sebagian besar pelaksanaan tugas kader TB pada kelompok umur $\leq 40$ tahun dan pada kelompok umur $>40$ tahun masih kurang, namun kader TB pada kelompok umur $>40$ tahun cenderung lebih dapat melaksanakan tugas dengan baik. Hal ini dikarenakan kader TB yang memasuki usia lebih tua telah memiliki lebih banyak pengalaman dan cenderung akan lebih teliti serta mempunyai rasa tanggung jawab yang tinggi dalam menekuni suatu pekerjaan. Notoatmodjo (2007) juga menyatakan bahwa perubahan perilaku seseorang dapat disebabkan oleh proses pendewasaan. Meningkatnya usia berbanding lurus terhadap kemampuan seseorang dalam pengambilan keputusan, pengendalian emosi, berpikir secara rasional serta meningkatkan toleransi terhadap pandangan orang lain (Notoatmodjo, 2007).

Berdasarkan karakteristik jenis kelamin, kader TB yang berjenis kelamin laki-laki sebagian besar pelaksanaan tugasnya baik, sedangkan kader TB yang berjenis kelamin perempuan pelaksanaan tugasnya sebagian besar masih kurang. Kader TB yang berjenis kelamin laki-laki pada umumnya memiliki fisik yang lebih kuat dan tidak mudah lelah daripada yang berjenis kelamin perempuan, selain itu orang yang berjenis kelamin laki-laki cenderung lebih jarang mengeluh terkait kondisi dalam melaksanakan tugas di luar ruangan seperti cuaca yang panas atau karena kelelahan. Hal ini sejalan dengan 
pernyataan Irwan (2017) bahwa perbedaan perilaku berdasarkan jenis kelamin salah satunya pada pembagian pekerjaan yang dimungkinkan oleh karena adanya perbedaan faktor hormonal dan struktur fisik. Perilaku perempuan sebagian besar didasari oleh perasaan, sedangkan perilaku laki-laki cenderung didasari atas pertimbangan yang sesuai fakta atau rasional (Irwan, 2017).

Kader TB yang memiliki tingkat pendidikan tergolong rendah maupun kader TB yang memiliki tingkat pendidikan tergolong tinggi sama-sama menunjukkan bahwa sebagian besar pelaksanaan tugasnya masih kurang. Namun, kader TB yang memiliki tingkat pendidikan tergolong rendah cenderung lebih dapat melaksanakan tugas dengan baik. Hal ini sejalan dengan pernyataan Ratnasari (2015) dalam penelitiannya bahwa tidak adanya hubungan antara tingkat pendidikan dengan pencapaian kinerja petugas TB paru dikarenakan walaupun dengan berpendidikan tinggi, tidak akan menjamin akan menghasilkan kinerja yang baik (Ratnasari, 2015). Kader TB yang memiliki tingkat pendidikan tergolong rendah cenderung lebih dapat melaksanakan tugas dengan baik tidak dilihat berdasarkan pendidikan formal yang diperoleh, melainkan pendidikan diluar sekolah seperti pengalamannya yang lebih banyak sehingga pengembangan pengetahuan serta keterampilan yang dimiliki lebih baik untuk dapat melaksanakan tugas dengan baik pula. Diharapkan orang yang memiliki pendidikan tinggi juga akan memiliki pengetahuan yang lebih luas, namun perlu ditekankan bahwa orang yang berpendidikan rendah juga belum tentu akan memiliki pengetahuan yang rendah. Peningkatan pengetahuan dapat terjadi tidak hanya melalui perantara pendidikan formal, namun juga dapat diperoleh melalui pendidikan diluar bangku sekolah atau non formal (Putri, 2012).

Kader TB di Kabupaten Badung yang memiliki pekerjaan lain selain sebagai kader maupun yang tidak memiliki pekerjaan lain, sama-sama belum dapat melaksanakan tugas dengan baik. Namun, dari pelaksanaan tugas yang kurang tersebut, kader TB yang memiliki pekerjaan lain selain sebagai kader cenderung lebih dapat melaksanakan tugas dengan baik. Menurut Nisa dkk (2017), apabila seorang kader memiliki pekerjaan lain, maka kader tersebut tidak akan memiliki waktu yang cukup dalam melakukan tanggung jawabnya sebagai kader di masyarakat. Hal tersebut bertolak belakang dengan keadaan responden di lapangan. Kader TB yang memiliki pekerjaan lain selain sebagai kader jauh lebih dapat melaksanakan tugas dengan baik dikarenakan tuntutan pekerjaan yang lebih banyak akan menjadikan kader tersebut lebih dapat memanajemen waktu yang dimiliki dengan baik, antara tugasnya sebagai kader maupun pekerjaan lain yang ditekuni. Hal ini didukung oleh pernyataan Wulandari (2013) bahwa orang yang tidak memiliki pekerjaan dan hanya berada di lingkungan rumah akan memiliki dampak pada keterbatasan memperoleh informasi terkait suatu pekerjaan. Informasi baru tentang 
kesehatan dan upaya pencegahan pada umumnya lebih cepat diterima pada orang yang bekerja melalui lingkungan sosial baik itu di tempat kerja maupun di sekitar tempat kerja, sehingga orang yang memiliki pekerjaan sebagian besar akan memiliki perilaku yang baik terhadap pekerjaan tersebut (Wulandari, 2013).

Berdasarkan reward yang diperoleh, kader TB di Kabupaten Badung yang sudah pernah memperoleh reward maupun kader TB yang belum pernah memperoleh reward sama-sama belum dapat melaksanakan tugas dengan baik. Kendati demikian, dari pelaksanaan tugas yang kurang tersebut, kader TB yang belum pernah memperoleh reward cenderung lebih banyak yang dapat melaksanakan tugasnya dengan baik. Pernyataan ini didukung oleh pendapat Wisnuwardani (2012) yang menyatakan bahwa kelemahan insentif yang berupa uang tunai adalah apabila kader memperoleh gaji atau imbalan, kader tersebut akan merasa bahwa diri mereka sudah seperti karyawan pemerintah atau lembaga swadaya masyarakat, bukan lagi sebagai pelayan masyarakat. Oleh karena itu, insentif berupa uang dapat menghilangkan semangat serta rasa kesukarelaan yang dimiliki oleh kader (Wisnuwardani, 2012).

Kader TB di Kabupaten Badung yang memperoleh pelatihan dalam kategori baik maupun yang memperoleh pelatihan dalam kategori kurang, samasama belum dapat melaksanakan tugas dengan baik. Namun, dari sebagian besar pelaksanaan tugas yang kurang tersebut, kader TB yang memiliki riwayat pelatihan baik cenderung lebih dapat melaksanakan tugas dengan baik. Hal ini sejalan dengan pernyataan Islam (2013) bahwa penemuan kasus yang meningkat sebanyak 3,9\% dapat terjadi pada kader yang telah mengikuti pelatihan (S. Islam, 2013). Pelatihan yang diperoleh berbanding lurus dengan pelaksanaan tugas, semakin sering memperoleh pelatihan maka semakin baik pelaksanaan tugas yang dilakukan. Hal ini dikarenakan pelatihan dapat dimanfaatkan oleh kader TB sebagai wadah dalam pengembangan pengetahuan yang dimiliki. Semakin sering kader TB tersebut mengikuti pelatihan, maka semakin banyak tambahan pengetahuan yang diperoleh. Fadhilah dkk (2014) juga menyebutkan pernyataan yang serupa, bahwa pelatihan yang diperoleh memberikan cukup banyak manfaat, seperti menambah pengetahuan terkait penyakit $\mathrm{TB}$, dari sebelumnya sama sekali tidak tahu menjadi tahu, menambah pengalaman serta sebagai bekal dalam praktik penemuan kasus TB. Melalui pelatihan akan menjadikan kader lebih tanggap, terampil dan cekatan dalam menentukan tindakan yang harus diambil karena sudah dibekali dengan ilmu. Pelatihan juga dapat dijadikan sebagai wadah bagi pengembangan pengetahuan secara informal (Fadhilah, 2014).

Dilihat dari tingkat pengetahuan, kader TB yang memiliki pengetahuan baik maupun yang memiliki pengetahuan kurang, sama-sama belum dapat melaksanakan tugas dengan baik. Walaupun sebagian besar pelaksanaan tugas kader TB masih kurang, kader TB yang memiliki pengetahuan baik cenderung lebih dapat melaksanakan 
tugas dengan baik. Hal ini sejalan dengan pernyataan Gopalan (2012) bahwa pengetahuan tersebut merupakan hasil "tahu" yang dimiliki seseorang setelah melalui penginderaan dengan panca indera manusia terhadap suatu objek, dimana sebagian besar pengetahuan manusia diperoleh melalui mata dalam melihat dan telinga dalam mendengar. Tindakan seseorang dipengaruhi oleh domain yang sangat penting, yaitu pengetahuan. Perilaku yang didasari oleh suatu pengetahuan akan lebih kekal daripada perilaku yang tidak didasari oleh pengetahuan (Gopalan, 2012). Hal ini dikarenakan kader $\mathrm{TB}$ yang memiliki pengetahuan baik akan lebih dapat menentukan keputusan yang lebih baik jika akan melaksanakan tugas. Kader TB yang memiliki pengetahuan baik juga tahu lebih banyak hal terkait pelaksanaan tugasnya, seperti apa manfaat maupun dampak yang dirasakan apabila melakukan maupun tidak melakukan tugas dengan baik sehingga mempengaruhi perilakunya dalam melaksanakan tugas. Menurut Notoatmodjo (2014), pengetahuan akan muncul ketika seseorang melibatkan akal budinya dalam mengenali suatu benda atau kejadian tertentu yang sebelumnya belum pernah dilihat ataupun dirasakan. Adanya pengetahuan akan menentukan seseorang dalam berperilaku. Seseorang yang memiliki pengetahuan tinggi, sebelum melakukan suatu tindakan akan memikirkannya dengan lebih matang. Seseorang tersebut cenderung akan memperhatikan apa akibat atau dampak yang akan diterima apabila melakukan suatu tindakan (Notoatmodjo, 2014).

\section{SIMPULAN}

Pelaksanaan tugas kader TB di Kabupaten Badung sebagian besar masih kurang. Hal ini dikarenakan sebagian besar kader TB masih belum terlibat aktif dalam kegiatan pendampingan pengobatan pada pasien TB. Adapun temuan yang diperoleh dalam penelitian ini adalah, dari pelaksanaan tugas yang kurang tersebut, kader TB pada kelompok usia > 40 tahun, berjenis kelamin laki-laki, memiliki tingkat pendidikan tergolong rendah, memiliki pekerjaan lain selain sebagai kader, belum pernah memperoleh reward, memiliki riwayat pelatihan baik serta memiliki tingkat pengetahuan yang baik cenderung lebih dapat melaksanakan tugas dengan baik.

\section{SARAN}

Dalam perekrutan kader selanjutnya, sebaiknya lebih dipertimbangkan agar merekrut kader yang berjenis kelamin laki-laki. Hal ini dikaitkan dengan tugas yang akan dilaksanakan kader tersebut sebagian besar berada diluar ruangan serta memerlukan struktur fisik yang lebih kuat.

\section{DAFTAR PUSTAKA}

Abshor, D. A. (2018). Faktor-Faktor Yang Berhubungan Dengan Perilaku Kader Community Tb-Hiv Care 'Aisyiyah Dalam Penemuan Suspek Tb Di Karesidenan Surakarta. Surakarta: Universitas Muhammadiyah Surakarta.

Anisah, I. A., Kusumawati, Y., \& Kirwono, B. (2017). Faktor-Faktor Yang Berhubungan Dengan Keaktifan 
Kader Communty Tb Care 'Aisyiyah

Surakarta. Jurnal Kesehatan, 10 (2), 47-57.

Dinas Kesehatan Kabupaten Badung. (2018). Profil Kesehatan Kabupaten Badung Tahun 2018.

Irwan. (2017). Etika dan Perilaku Kesehatan. Yogyakarta: CV.Absolute Media.

Jane Rahedi Ong'ang'o, C. M. (2014). The Effects on Tuberculosis Treatment Adherence from Utilising Community Health Workers : A Comparison of Selected Rural and Urban Settings in Kenya. PLoS ONE 9(2).

Megawati, Suriah, Ngatimin, R., \& Yani, A. (2018). Edukasi Tb Paru Pengetahuan Sikap Kader Posyandu Melalui Permainan Simulasi Monopoli. The Indonesian Journal of Health Promotion, 1 (1), 5-11.

Nisa, S. M., \& P.S., Y. D. (2017). Hubungan

$\begin{array}{lcr}\text { Antara } & \text { Karakteristik } & \text { Kader } \\ \text { Kesehatan } & \text { Dengan } & \text { Praktik } \\ \text { Penemuan } & \text { Tersangka } & \text { Kasus } \\ \text { Tuberkulosis Paru . Jurnal of Health } \\ \text { Education, 2 (1), } 94 .\end{array}$

Notoatmodjo, S. (2007). Promosi Kesehatan dan Ilmu Perilaku. Jakarta: Rineka Cipta.

Notoatmodjo, S. (2014). Ilmu Perilaku Kesehatan. Jakarta: Rineka Cipta.

Nur Fadhilah, E. N. (2014). Perilaku Kader dalam Penemuan Suspek Tuberkulosis. Jurnal Kesehatan Masyarakat Nasional 8(6), 280-283.
Putri, P. K. (2012). Pengaruh Tingkat Pendidikan, Pengetahuan, Sikap dan Terpaan Iklan Layanan Masyarakat KB Versi Shireen Sungkar dan Teuku Wisnu di TV terhadap Perilaku KB pada Wanita atau Pria dalam Usia Subur. Jurnal Interaksi, 46-56.

Ratnasari, D. (2015). Faktor-Faktor yang Berhubungan dengan Pencapaian Petugas terhadap Case Detection Rate (CDR) pada Program TB Paru di Kabupaten Rembang. Semarang: Universitas Negeri Semarang.

Saji Saraswathy Gopalan, S. M. (2012). Assesing Community Health Workers' Perfomance Motivation : a Mixed-methods Approach on India's Accredited Social Health Activists (ASHA) Programme. BMJ Open 2(1557), 1-10.

S. Islam, H. A. (2013). Training of Community Healthcare Providers and TB Case Detection in Bangladesh. Bangladesh : International Health 5(3), 7-223.

Wisnuwardani, R. W. (2012). Insentif Uang Tunai dan Peningkatan Kinerja Kader Posyandu. Jurnal Kesehatan Masyarakat Nasional 7(1), 44-48.

Wulandari, U. M. (2013). Hubungan Karakteristik dan Pengetahuan Ibu dengan Perilaku PSN-DBD di Kelurahan Sungai Jawi Pontianak Tahun 2013. Pontianak: Universitas Tanjungpura Pontianak.

Yani, D. I., Hidayat, R. A., \& Sari, C. W. (2018). Gambaran Pelaksanaan Peran Kader Tuberkulosis pada Program 
Arc. Com. Health • Juni 2020

p-ISSN 2302-139X e-ISSN 2527-3620

Vol. 7 No. 1: 52 - 62

DOTS di Kecamatan Bandung Kulon.

Jurnal Keperawatan Komprehensif, 4

(2), 58-67. 